\title{
EL DERECHO DE REPARACIÓN A LAS VÍCTIMAS EN EL DERECHO INTERNACIONAL. UN ESTUDIO COMPARATIVO ENTRE EL DERECHO INTERNACIONAL DE RESPONSABILIDAD ESTATAL Y LOS PRINCIPIOS BÁSICOS DE REPARACIÓN DE VÍCTIMAS DE DERECHOS HUMANOS
}


I. EL DERECHO DE REPARACIÓN EN EL DERECHO INTERNACIONAL DE LA RESPONSABILIDAD ESTATAL. 1. El contexto multilateral: la restauración y el mantenimiento del imperio del derecho. 2. La finalidad de la reparación. II. EL DERECHO DE REPARACIÓN EN EL DERECHO INTERNACIONAL DE LOS DERECHOS HUMANOS. 1. Origen y desarrollo de los Principios y Directrices Básicos sobre Reparaciones. 2. Contenido de los Principios y Directrices Básicos sobre Reparaciones. 2.1. Ámbito de aplicación. 2.1.1. Las víctimas. 2.1.2. Las violaciones. 2.2. Estructura de los Principios y Directrices Básicos sobre Reparaciones. 2.2.1. Prevención de las violaciones. 2.2.2. Investigación de las violaciones y enjuiciamiento y castigo a los autores. 2.2.3. Acceso equitativo y efectivo a la justicia. 2.2.4. La reparación y sus formas. III. CONCLUSIONES. 


\title{
EL DERECHO DE REPARACIÓN A LAS VÍCTIMAS EN EL DERECHO INTERNACIONAL. UN ESTUDIO COMPARATIVO ENTRE EL DERECHO INTERNACIONAL DE RESPONSABILIDAD ESTATAL Y LOS PRINCIPIOS BÁSICOS DE REPARACIÓN DE VÍCTIMAS DE DERECHOS HUMANOS*
}

\author{
POR \\ LUIS M. CRUZ \\ Profesor Contratado Doctor de Filosofía del Derecho \\ Universidad de Coruña
}

Antes de que se desarrollase un derecho internacional de los derechos humanos, las violaciones de estos derechos en el ámbito internacional encontraban respuesta bajo el derecho internacional de responsabilidad estatal ${ }^{1}$. Este cuerpo

* El presente trabajo se enmarca dentro del Proyecto de Investigación «Del Discurso de la derrota al discurso del diálogo: justicia transicional, memoria histórica y constitución» financiado por el Ministerio de Educación y Ciencia (SEJ2007-64461).

${ }^{1}$ Cfr. Shelton, D.: Remedies in International Human Rights Law, 2. ${ }^{a}$ ed., Oxford, Oxford University Press, 2005, p. 50. 
de derecho, particularmente la parte que concierne a los daños a los extranjeros, podía ser aplicable a las violaciones de derechos humanos llevadas a cabo por un Estado al infringir una obligación contenida en un tratado internacional o en el derecho internacional consuetudinario.

El derecho internacional de responsabilidad estatal requiere a un Estado que haga las pertinentes reparaciones cuando no ha cumplido, ya sea por acción u omisión, una obligación de derecho internacional. Es, por tanto, un derecho que se deriva de casos interestatales entre partes jurídicamente iguales. De ahí que, aunque las indemnizaciones pueden deberse a violaciones por parte de un Estado a personas individuales, las reparaciones son debidas al Estado del cual esas personas son nacionales. El Estado que daña a un individuo extranjero, indirectamente daña al Estado del que es nacional. Este Estado puede adoptar la reclamación como propia y demandar al Estado trasgresor ${ }^{2}$. Por ello, mientras que los nacionales cuyos derechos humanos son violados por el propio Estado no pueden acogerse a este cuerpo de derecho, los extranjeros, después de haber agotado todos los recursos internos, tienen esta vía indirecta para reclamar una reparación ${ }^{3}$.

Aunque existen diferencias significativas entre las circunstancias que rodean el derecho de reparaciones por daños a extranjeros y el debido a violaciones de derechos humanos, sin embargo, la comparación entre estos dos sistemas de reparación es interesante en orden a identificar los elementos comunes así como los elementos característicos de cada uno de ellos. En ambos contextos es necesario determinar si las víctimas tienen un derecho a una reparación, definir el término "víctima» y establecer el tipo de reparaciones que deben ser llevadas a cabo.

Para ello se analizarán los dos textos más importantes en el ámbito de reparación a las víctimas en el ámbito internacional y que reflejan las características esenciales de cada uno de los sistemas anteriormente mencionados. Por un lado, los Artículos sobre la Responsabilidad del Estado por hechos internacionalmente ilícitos, adoptados por la Comisión de Derecho Internacional de las $\mathrm{Na}$ ciones Unidas en 2001. Por otro lado, los Principios y Directrices Básicos sobre el Derecho de las Victimas de Violaciones Manifiestas de las Normas Internacionales de Derechos Humanos y de Violaciones Graves del Derecho Internacional Humanitario

2 Así, en el caso Corfu Channel, el Tribunal Internacional de Justicia reconoció que la indemnización por daños y perjuicios de dos barcos de guerra británicos y los costes de las pensiones y tratamiento médico de los muertos y los heridos de los miembros de la tripulación eran demandas competentes, pero que el dañado era el Estado. Cfr. Corfu Channel Case (UK v. Albania) (Merits), 1949 ICJ Rep. 1, 4.

${ }^{3}$ Cfr. SoHn, L. B.: «The New International Law: Protection of the Rights of Individuals Rather than Status». American University Law Review, 32, 1982, pp. 1-64. 
a Interponer Recursos y Obtener Reparaciones, aprobados por la Asamblea General de las Naciones Unidas en 2005. Estos textos articulan, cada uno en su ámbito, aquellos principios que han sido aplicados en el los tribunales internacionales y que gozan de un amplio consenso en el derecho internacional ${ }^{4}$.

\section{EL DERECHO DE REPARACIÓN EN EL DERECHO INTERNACIONAL DE LA RESPONSABILIDAD ESTATAL}

En agosto de 2001, la Comisión de Derecho Internacional de las Naciones Unidas, en su labor de codificación y desarrollo progresivo del derecho internacional, adoptó y envió a la Asamblea General, junto con un extenso comentario anexo, un texto de 59 artículos sobre la responsabilidad del Estado por hechos internacionalmente ilícitos. No obstante, recomendaba a la Asamblea General que no fuesen adoptados como un tratado. La Asamblea General, siguiendo la sugerencia de la Comisión, en su resolución 56/83 de 12 de diciembre de 2001, tomó nota de los artículos y los remitió a los gobiernos sin perjuicio de la cuestión de su futura aprobación o de otro tipo de medida.

El desarrollo de los Artículos sobre la Responsabilidad del Estado es fruto de un largo y prolífico trabajo. En 1953 la Asamblea General invitó a la Comisión de Derecho Internacional a llevar a cabo una codificación de la responsabilidad estatal en el ámbito internacional. Desde 1955 hasta la aprobación de los artículos, cinco relatores especiales han estado al frente (F.V. García-Amador, Roberto Ago, Willem Riphagen, Gaetano Arangio-Ruiz y James Crawford), realizando más de treinta informes 5 .

La arquitectura básica de los artículos en relación con la obligación a reparar procede de la estructura conceptual articulada por el Tribunal Permanente de Justicia Internacional en el caso Chorzów Factory ${ }^{6}$. De acuerdo con el Tribunal,

\footnotetext{
${ }^{4}$ En este sentido, este trabajo se centrará especialmente en el sistema de protección desarrollado bajo el amparo de las Naciones Unidas. No se hará referencia, por tanto, al alcance e impacto de las reparaciones a las víctimas en el sistema europeo y en el sistema interamericano, ni a los efectos generales que despliegan los pronunciamientos de dichas instancias internacionales.

${ }_{5}$ Cfr. al respecto, American Journal of International Law, 96, 2002, donde se recogen las ponencias del Symposium: The ILC's State Responsability Articles; y CRAWFORD, J.: The International Law Commission's Articles on State Responsability. Introduction, Text and Commentaries, Cambridge, Cambridge University Press, 2002.

${ }_{6}^{6}$ Factory at Chorzów Case (Germany v. Poland), 1928 PCIJ (ser. A) No. 17. Esta decisión surge a partir de una expropiación de una fábrica por el gobierno de Polonia, que el Tribunal entendió que violaba la Convención Germano-Polaca sobre la Alta Silesia del 15 de mayo de 1922.
} 
«es un principio de derecho internacional que el incumplimiento de un compromiso conlleva una obligación de hacer una reparación en una forma adecuada. La reparación por tanto es el complemento indispensable de un incumplimiento en la aplicación de una convención y no hay necesidad de que esté indicado en la convención misma ${ }^{7}$. Para ello, «la reparación debe, en la medida de lo posible, eliminar todas las consecuencias del acto ilegal y reestablecer la situación que, con toda probabilidad, habría existido si el acto no hubiera sido cometido. Reparación en especie, o, si esto no es posible, el pago de una suma correspondiente al valor de lo que la restitución en especie requeriría; la indemnización, si fuese necesario, por daños y perjuicios sufridos de lo que no fuese cubierto por la restitución en especie o el pago en su lugar - tales son los principios que servirían para determinar la cantidad de compensación debida por un acto contrario al derecho internacional ${ }^{8}$.

Estos principios interrelacionados - que un delito internacional genera una obligación de reparación, y que la reparación debe erradicar, en la medida de lo posible, las consecuencias del acto ilegal - son los fundamentos del derecho internacional y de los artículos de la Comisión de Derecho Internacional sobre reparaciones? .

Los tribunales internacionales han inferido de estos fundamentos un poder inherente para ofrecer reparaciones. Desde el momento en que es un principio de derecho internacional que toda violación de una obligación internacional crea un deber de reparar, un tribunal internacional con jurisdicción sobre una controversia tiene jurisdicción para conceder reparaciones al determinar que se ha llevado a cabo una infracción del derecho internacional ${ }^{10}$. Así, en el caso $L a-$ Grand, el Tribunal Internacional de Justicia afirmó su competencia, estableciendo que « $[\mathrm{d}]$ onde existe jurisdicción sobre una controversia sobre una cuestión particular, no se requiere una base distinta de jurisdicción por parte del Tribunal para considerar las reparaciones que una parte ha solicitado por la infracción de la obligación ${ }^{11}$.

Los Artículos sobre la Responsabilidad del Estado están divididos en cuatro partes. En la primera se determinan las reglas concernientes a la infracción de la

7 Chorzów Factory, Jurisdiction, 21.

${ }^{8}$ Chorzów Factory, Indemnity, 47.

9 Cfr. Shelton, D.: «Righting Wrongs: Reparations in the Articles on State Responsability», American Journal of International Law, 96, 2002, pp. 835-837.

${ }^{10}$ Cfr. Brownlie, I.: «Remedies in the International Court of Justice», en Lowe, V. y FITZMAURICE, M. (eds.), Fifty Years of the International Court of Justice. Essays in Honour of Sir Robert Jennings, Cambridge, Cambridge University Press, 1996, pp. 557-558.

${ }^{11}$ LaGrand Case (Germany v. U.S.) 27 de junio de 2001, 48. 
obligación internacional, esto es, del hecho internacionalmente ilícito del Estado. En la segunda, se establece el contenido de la responsabilidad internacional del Estado (cesación, garantías de no repetición, reparación, formas de reparación). En la tercera, se configuran los modos de hacer efectiva la responsabilidad internacional del Estado. La última parte está dedicada a una serie de disposiciones generales.

Los artículos que se refieren a la reparación reflejan dos premisas conceptuales $^{12}$. En primer lugar, las reparaciones son consideradas en un contexto multilateral más que exclusivamente bilateral, enfatizando la restauración y mantenimiento del imperio del derecho y elaborando las consecuencias de una violación grave de las obligaciones emanadas de normas imperativas del derecho internacional. En segundo lugar, el propósito y ámbito de las reparaciones están dirigidos a la reparación plena y aparecen limitados a medidas de recuperación, excluyendo sanciones o multas.

\section{El contexto multilateral: la restauración y el mantenimiento del imperio del derecho}

Tradicionalmente, las consecuencias de una violación del derecho internacional han sido consideradas como una cuestión bilateral, afectando únicamente a los dos Estados en cuestión: el responsable de la violación y el lesionado. Sin embargo, la proliferación de convenios multilaterales ha hecho que esta aproximación tradicional sea inadecuada, ya que, aunque una violación de un convenio de este tipo pueda no causar un daño específico a un Estado, puede debilitar la efectividad del régimen jurídico y el respecto por el imperio del derecho ${ }^{13}$.

Los Artículos sobre la Responsabilidad del Estado responden, precisamente, al desafío de asegurar el imperio del derecho internacional. Así, las consecuencias jurídicas que se siguen de un acto ilícito internacional, determinadas en los seis primeros artículos, suponen la existencia, no sólo de unos derechos específicos de la parte lesionada, sino de una obligación internacional del Estado responsable ante la comunidad internacional como un todo. De ahí que una de las primeras obligaciones que tiene el Estado infractor es la de cesar el acto ilícito y, si las circunstancias lo exigen, ofrecer seguridades y garantías adecuadas de no repetición.

${ }^{12}$ Cfr. Shelton, D.: «Righting Wrongs: Reparations in the Articles on State Responsability», cit., p. 838.

13 Cfr. Crawford, J.: The International Law Commission's Articles on State Responsability: Introduction, Text and Commentaries, cit., "Commentaries», pt. 2, cap. I, General Principles, para. 1. 
La función del cese del acto ilícito es poner fin a la violación del derecho internacional y salvaguardar la validez y efectividad de las reglas subyacentes. La obligación del Estado responsable de cesar la agresión protege, así, tanto los intereses del Estado lesionado como los intereses de la comunidad internacional ${ }^{14}$. El énfasis en el imperio del derecho también conlleva que el cese de la violación no sea una opción del Estado lesionado - la violación debe cesar, incluso si el Estado lesionado no lo demanda - ni está sujeta a los límites de la proporcionalidad — como sí lo están las formas de reparación-.

Sin lugar a dudas, es en el capítulo tercero, dedicado a la responsabilidad internacional generada por la violación grave de obligaciones emanadas de normas imperativas del derecho internacional, donde mejor se refleja esta finalidad. El artículo 40 delimita el ámbito del capítulo, definiendo la violación grave como aquella que implica el incumplimiento flagrante o sistemático de la obligación por el Estado responsable. El artículo 41 describe las consecuencias que acarrea la violación: la obligación por parte de los Estados de cooperar para poner fin, por medios lícitos, a toda violación grave; y, la obligación de no reconocer como lícita las situaciones creadas por las violaciones graves, ni prestar ayuda o asistencia para mantener esas situaciones.

De esta forma, estos dos artículos afirman la existencia en el ámbito internacional de normas de ius cogens y obligaciones erga omnes de acción y abstención. A pesar de que ni la práctica internacional ni la jurisprudencia tanto nacional como internacional de los tribunales de justicia han discutido o aplicado el concepto de normas imperativas, los Artículos sobre Responsabilidad del Estado lo han incluido para prohibir aquellos actos que han llegado a ser intolerables debido a la amenaza que representan para supervivencia de los Estados y los valores humanos más básicos ${ }^{15}$.

\section{La finalidad de la reparación}

En relación con la reparación, los Artículos sobre la Responsabilidad del Estado siguen el enfoque que sirve de base a la mayoría de las decisiones internacionales, incluido el caso Chorzów Factory, a saber, la justicia restaurativa ${ }^{16}$. Es decir, buscan rectificar el daño realizado en la parte lesionada y corregir la injusticia res-

\footnotetext{
${ }^{14}$ Cfr. Ibid., "Commentaries», art. 30, para. 5.

15 Cfr. Ibid., "Commentaries", art. 40, para. 2-3.

16 Cfr. Shelton, D.: «Righting Wrongs: Reparations in the Articles on State Responsability», cit., p. 844.
} 
taurando el status quo ante. Las reparaciones están diseñadas, por tanto, no para disuadir o castigar al Estado infractor, sino para situar a la parte agraviada en al misma posición que estaría si el acto ilícito no se hubiera cometido.

El artículo 31 recoge la regla general del caso Chorzów Factory de que el Estado responsable está obligado a reparar íntegramente el perjuicio causado, incluyendo todo daño, tanto material como moral, causado por el acto internacionalmente ilícito. El artículo 32 añade que el Estado responsable no puede invocar las disposiciones de derecho interno como justificación para no proveer de reparaciones.

Las formas de reparación, contenidas en los artículos 34 a 39, son la restitución, la indemnización y la satisfacción, estableciéndose una jerarquía entre ellas. Se exige en primer lugar el restablecimiento del status quo ante, a través de la restitución, siempre y cuando no sea materialmente imposible y no entrañe una carga totalmente desproporcionada con relación al beneficio que derivaría de la restitución en lugar de la indemnización.

Si el daño no puede ser reparado por la restitución, el Estado responsable está obligado a indemnizar el daño causado, susceptible de evaluación financiera, incluido el lucro cesante en la medida en que éste pueda comprobarse. En la medida en que la finalidad de las medidas es la reparación íntegra, el pago por daños y perjuicios debe tener un propósito puramente compensatorio, en ningún caso puede ser ejemplarizante o punitivo.

Finalmente, la satisfacción entra en juego únicamente como una medida excepcional y en ciertos casos, cuando el perjuicio no pueda ser reparado mediante restitución o indemnización. La satisfacción puede consistir en un reconocimiento de la violación, una expresión de pesar, una disculpa formal o cualquier otra modalidad adecuada siempre y cuando no sea desproporcionada con relación al perjuicio y no adopte una forma humillante para el Estado responsable. La razón de este carácter excepcional radica en que su utilización puede ser considerada más como una medida punitiva que restaurativa.

\section{EL DERECHO DE REPARACIÓN EN EL DERECHO INTERNACIONAL DE LOS DERECHOS HUMANOS}

El derecho de las víctimas a una reparación es una parte del derecho internacional, contenido en tratados de derechos humanos tanto regionales ${ }^{17}$ como

17 Vid., Convenio Europeo para la Protección de los Derechos Humanos y de las Libertades Fundamentales, art. 41; Convención Interamericana sobre Derechos Humanos, art. 63; Carta Africana sobre los Derechos Humanos y de los Pueblos, art. 21. 
internacionales ${ }^{18}$, así como en normas de derecho internacional humanitario ${ }^{19} \mathrm{y}$ de derecho penal internacional ${ }^{20}$.

Asimismo, distintas declaraciones, resoluciones y otros textos adoptados por las Naciones Unidas reconocen este derecho de las víctimas. Sin duda, el mayor esfuerzo sobre la materia ha sido realizado por la Subcomisión de Promoción y Protección de los Derechos Humanos y la Comisión de Derechos Humanos de las Naciones Unidas en la elaboración de un conjunto de principios internacionales sobre reparación a las víctimas de violaciones de derechos humanos. Veinte años de estudio, negociaciones y borradores culminaron con la aprobación por la Asamblea General de las Naciones Unidas de los Principios y Directrices Básicos sobre el Derecho de las Victimas de Violaciones Manifiestas de las Normas Internacionales de Derechos Humanos y de Violaciones Graves del Derecho Internacional Humanitario a Interponer Recursos y Obtener Reparaciones (A/RES/60/147).

\section{Origen y desarrollo de los Principios y Directrices Básicos sobre Reparaciones}

La Subcomisión para la Prevención de la Discriminación y Protección de las Minorías (ahora, Subcomisión para Promoción y Protección de los Derechos Humanos), comenzó sus trabajos sobre reparaciones con la resolución 1988/11 de 1 de septiembre de 1988, en la que se reconocía que todas las víctimas de violaciones graves de derechos humanos y libertades fundamentales deberían tener derecho a una restitución, a una indemnización imparcial y justa, y a los medios para una rehabilitación lo más completa posible por el daño sufrido. Para ello, encargó en 1989 a Theodoor van Boven un estudio sobre «el derecho a la restitución, indemnización y rehabilitación de las víctimas de violaciones graves de derechos humanos y libertades fundamentales» con el fin de desarrollar unos principios y directrices básicos sobre reparaciones.

En 1993, Theo van Boven presentó un informe final al que le anexó un proyecto de principios sobre restitución, indemnización y rehabilitación (E/CN.4/Sub.2/1993/8). Para van Boven, las violaciones flagrantes de los de-

18 Vid. Pacto Internacional sobre Derechos Civiles y Politicos, arts. 9(5) y 14(6); Convención Internacional sobre la Eliminación de todas las formas de Discriminación Racial, art. 6; y, Convención contra la Tortura y otros Tratos o Penas Crueles, Inhumanos o Degradantes, art. 14; entre otros.

19 Convención de la Haya. Convención (IV) relativa a las Leyes y Costumbres de la Guerra Terrestre, art. 3; Protocolo I Adicional a la Convención de Ginebra, art. 91.

${ }^{20}$ Estatuto de Roma de la Corte Penal Internacional, art. 75. 
rechos humanos y las libertades fundamentales, particularmente cuando se han cometido a escala masiva, son por su mismo carácter irreparables. En tales casos, no hay reparación o compensación que guarde una relación proporcional con el grave daño causado a las víctimas. Sin embargo, la norma más elemental de justicia exige, a su juicio, que se determine claramente la responsabilidad de los culpables y se salvaguarden en la mayor medida posible los derechos de las víctimas.

Posteriormente, van Boven, a petición de la Comisión, revisó el proyecto de principios y directrices básicos y presentó en 1996 una nueva versión (E/CN.4/Sub.2/1996/17), y en 1997 una corrección de esta última versión (E/CN.4/1997/104). A pesar de los cambios estructurales de las nuevas versiones, hay pocos cambios sustanciales en las disposiciones desde 1993 a 1997.

En 1998, la Comisión solicitó a un experto independiente, Cherif Bassiouni, que preparase una versión revisada de los Principios y Directrices Básicos sobre Reparaciones elaborados por van Boven, teniendo en cuenta las opiniones y comentarios de los Estados y las organizaciones intergubernamentales y no gubernamentales. Bassiouni presentó un informe en 1999 (E/CN.4/1999/65) y un informe final en el 2000, al que adjuntó la cuarta versión del proyecto de Principios y Directrices Básicos sobre Reparaciones (E/CN.4/2000/62).

En septiembre de 2002, la Oficina para el Alto Comisionado para los Derechos Humanos de Naciones Unidas, en cooperación con el gobierno de Chile, organizó la primera de una serie de tres reuniones consultivas con el propósito de elaborar una versión definitiva de los Principios y Directrices Básicos sobre Reparaciones. Bajo la presidencia de Alejandro Salinas y la participación de van Boven y Bassiouni, así como de los delegados de los Estados, organizaciones gubernamentales y no gubernamentales, las reuniones consultivas sirvieron para revisar, redefinir y aclarar el texto definitivo. Dado que el principal objetivo del proceso fue el de sistematizar el extenso cuerpo jurídico que regulaba el derecho a un recurso y a una reparación, estas reuniones tenían que guardar un frágil equilibrio entre la necesidad de contar con los apoyos intergubernamentales, tomando en cuenta las posturas de los distintos Estados, y la necesidad de que el texto reflejase acertadamente una comprensión universal y coherente de los principios sobre el derecho de las víctimas a interponer recursos y obtener reparaciones. En este sentido, uno de los problemas más serios lo constituyó la referencia al derecho internacional humanitario, lo cual hizo que trece Estados se abstuvieran de votar a favor del texto ${ }^{21}$. Finalmente, el 21 de diciembre de

${ }^{21}$ Los Estados que se abstuvieron fueron: Alemania, Arabia Saudita, Australia, Egipto, Eritrea, Estados Unidos, Etiopía, India, Mauritania, Nepal, Qatar, Sudán y Togo. 
2004, Salinas remitió a la Comisión de Derechos Humanos el proyecto definitivo (E/CN.4/2005/59).

Los Principios y Directrices Básicos sobre el Derecho de las Victimas de Violaciones Manifiestas de las Normas Internacionales de Derechos Humanos y de Violaciones Graves del Derecho Internacional Humanitario a Interponer Recursos y Obtener Reparaciones fueron aprobados por la Comisión de Derechos Humanos, en su resolución 2005/25, de 19 de abril de 2005, por el Consejo Económico y Social, en su resolución 2005/30, de 25 de julio de 2005, y, finalmente, por la Asamblea General, en su resolución A/RES/60/147, de 16 de diciembre de $2005^{22}$.

\section{Contenido de los Principios y Directrices Básicos sobre Reparaciones}

El texto de los Principios y Directrices Básicos sobre Reparaciones contiene 13 secciones y 27 principios y directrices, sin que exista una distinción operativa entre estos dos términos. Su propósito es claro: definir el alcance del derecho a un recurso y a una reparación y defender el imperio del derecho y el interés público disuadiendo violaciones futuras. Ahora bien, no pretenden establecer nuevas obligaciones jurídicas internacionales o nacionales, sino únicamente indicar los mecanismos, modalidades, procedimientos para el cumplimiento de las obligaciones jurídicas existentes conforme a las normas internaciones de derechos humanos y al derecho internacional humanitario. En este sentido, pretenden reflejar las normas mínimas del derecho internacional sobre la materia.

El preámbulo cita las distintas disposiciones de tratados globales y regionales y otros instrumentos internacionales que proveen un derecho a acceder a los mecanismos de justicia y reparación, a la vez que anima a fomentar el establecimiento, fortalecimiento y ampliación de fondos nacionales para indemnizar a las víctimas, juntamente con el rápido establecimiento de derechos y recursos apropiados para ellas. Asimismo recuerda la obligación de enjuiciar a los perpetradores de determinados crímenes internacionales conforme a las obligaciones internacionales de los Estados.

${ }^{22}$ Cfr. al respecto, Shelton, D.: «The United Nations Principles and Guidelines on Reparations: Context and Contents», en DE Feyter, K., PARmentier, S., Bossuyt, M. y Lemmens, P. (eds.), Out of the Ashes. Reparation for Victims of Gross and Systematic Human Rights Violations, Intersentia, Antwerpen-Oxford, 2005, pp. 11-33; y, el Informe de la ONG internacional REDREss: Implementando los derechos de las víctimas, Redress, Londres, 2006. 


\section{1. Ámbito de aplicación}

Los Principios y Directrices Básicos sobre Reparaciones están orientados hacia las víctimas y aplicados a las violaciones manifiestas de las normas internacionales de derechos humanos y a las violaciones graves del derecho internacional humanitario, que por su carácter muy grave constituyen una afrenta a la dignidad humana.

\subsubsection{Las víctimas}

Teniendo en cuenta la Declaración sobre los principios fundamentales de justicia para las victimas de delitos y del abuso de poder, aprobada por la Asamblea General de Naciones Unidas (A/RES/40/34, de 29 de noviembre de 1985), los Principios y Directrices Básicos sobre Reparaciones definen como "víctima» a "todas persona que haya sufrido individual o colectivamente, incluidas lesiones físicas o mentales, sufrimiento emocional, pérdidas económicas o menoscabo sustancial de sus derechos fundamentales, como consecuencia de acciones $u$ omisiones que constituyan una violación manifiesta de las normas internacionales de derechos humanos o una violación grave del derecho internacional humanitario. Cuando corresponda, y en conformidad con el derecho interno, el término víctima también comprenderá a la familia inmediata o las personas a cargo de la víctima directa y a las personas que hayan sufrido daños al intervenir para prestar asistencia a víctimas en peligro o para impedir la victimización $»^{23}$. Asimismo, una persona «será considerada víctima con independencia de si el autor de la violación ha sido identificado, aprehendido, juzgado o condenado y de la relación familiar que pueda existir entre el autor y la víctima» ${ }^{24}$.

De este modo, pueden señalarse tres elementos fundamentales en el concepto de "víctima». En primer lugar, en relación con los daños o pérdidas que pueden ser inflingidos (daños físicos y psíquicos, daños materiales y daños políticos y jurídicos), existen distintos tipos de víctimas, que pueden producirse tanto por acciones positivas como por omisiones. En segundo lugar, en relación con los tipos de víctimas, junto a la persona que ha sufrido directamente la violación, se tienen en cuenta aquellas personas que por su cercanía han sufrido indirectamente la violación. Entre las víctimas indirectas se incluye a la familia inmediata, los dependientes directos de la víctima y todas aquellas personas que

23 Principios y Directrices Básicos sobre Reparaciones, A/RES/60/147, Principio 8.

${ }^{24}$ Ibid., Principio 9. 
hayan sufrido algún daño al prestar asistencia a la víctima o al intentar impedir la violación (por ejemplo, los abogados defensores de los derechos humanos o los médicos que asisten a las víctimas, pueden ser ellos mismos, al realizar su labor, maltratados, intimidados, interrogados, arrestados, etc.). En tercer lugar, la condición de víctima se adquiere independientemente de si el autor es identificado o si existe alguna relación particular entre la víctima y el autor de la violación. Este elemento es especialmente relevante en los casos de las violaciones graves o masivas donde es difícil, incluso imposible, identificar a su autor o autores, y las víctimas sólo pueden proveer evidencia sobre el daño recibido. Los Principios y Directrices Básicos sobre Reparaciones reconocen así que para ser acreedor de una reparación no hay que esperar a que las autoridades identifiquen al autor.

\subsubsection{Las violaciones}

Como se ha indicado, los Principios y Directrices Básicos sobre Reparaciones se encuentran restringidos a las violaciones manifiestas de las normas internacionales de derechos humanos y a las violaciones graves del derecho internacional humanitario, que por su carácter muy grave constituyen una afrenta a la dignidad humana. Esto no quiere decir, sin embargo, que el derecho a la reparación surja sólo en esos casos. No debe interpretarse, por tanto, de una manera restrictiva. Ahora bien, las consecuencias jurídicas que se derivan de este tipo de violaciones son muy específicas (el derecho a un recurso judicial, jurisdicción universal, la no prescripción, los tipos de reparaciones), y no pueden aplicarse a otros casos (como puede ser la violación del derecho a la libertad de expresión).

En la primera versión de 1993, van Boven presentó una lista no exhaustiva de este tipo de violaciones, tomando como base distintas normas, tratados de derechos humanos o proyectos de códigos ${ }^{25}$. Así, incluyó en esta categoría, el genocidio, la esclavitud y las prácticas similares, las ejecuciones sumarias o arbitrarias, la tortura y los tratos o penas crueles, inhumanos o degradantes, las desapariciones forzadas, la detención arbitraria y prolongada, la deportación o el traslado forzoso de poblaciones, y la discriminación sistemática, en particular por motivos de raza o sexo. No obstante, en las versiones posteriores se eliminó la referencia expresa a una lista de violaciones, ya que, en opinión de algunos de los

25 En concreto, van Boven utilizó el Proyecto de 1991 del Código de Crímenes contra la Paz y la Seguridad de la Humanidad realizado por la Comisión de Derecho Internacional, el artículo 3 común a los Convenios de Ginebra del 12 de agosto de 1949 y el Third Restatement of the Foreign Relations Law of the United States 1987 (sec. 702). 
participantes en las reuniones de consultas previas, se consideró que la lista incluía principios de diferente carácter y valor ${ }^{26}$.

Hay que tener presente que los términos «manifiesta» y "grave» se refieren fundamentalmente a la naturaleza de las violaciones y no sólo a las violaciones cometidas a una escala masiva o con una política o patrón sistemático. Para van Boven, que utilizó la palabra «flagrante» para referirse a este tipo de violaciones, la gravedad reside no sólo en cómo se han llevado a cabo, sino fundamentalmente al tipo de derechos humanos que se violan, independientemente del contexto en el que son cometidas ${ }^{27}$.

La internacionalización de las violaciones no depende, por tanto, de su carácter internacional. Es la naturaleza manifiesta de los crímenes lo que los hace internacionales. Los intereses que protegen las disposiciones relativas a los derechos humanos no son atribuibles a un determinado Estado, sino a la comunidad internacional en su conjunto y generan, por tanto, obligaciones erga omnes. En este sentido, el concepto de "Estado lesionado» no debe limitarse a los derechos e intereses infringidos que pertenecen de inmediato a ese Estado, sino que también debe aplicarse a los derechos e intereses que surgen de un tratado o en una convención multilateral o de una norma del derecho internacional consuetudinario y se han creado para la protección de los derechos humanos y las libertades fundamentales. Por ello, la responsabilidad del Estado no sólo entra en juego con respecto a los Estados que participan en el orden jurídico internacional, sino también más directamente con respecto a las personas de la jurisdicción del Estado infractor, cuando esas personas son víctimas de violaciones de derechos humanos internacionalmente reconocidos cometidos por ese Estado.

\subsection{Estructura de los Principios y Directrices Básicos sobre Reparaciones}

Las dos primeras secciones del texto determinan el contenido y el ámbito de la obligación de respetar, asegurar que se respeten y aplicar las normas internacionales de derechos humanos y el derecho internacional humanitario. En concreto, conlleva cuatro deberes fundamentales ${ }^{28}:$ a) la adopción de disposiciones legislativas y administrativas y otras medidas apropiadas para impedir las violaciones; b) la investigación de las violaciones de forma eficaz, rápida, completa e imparcial y, en su caso, la adopción de medidas contra los presuntos responsa-

${ }^{26}$ Cfr. Informe E/CN.4/Sub. 2/1994/22, párrafo 20.

27 Cfr. Informe E/CN.4/Sub. 2/1993/8, párrafos 8-13.

28 Principios y Directrices Básicos sobre Reparaciones, A/RES/60/147, Principio 3. 
bles; c) la dotación a las víctimas de un acceso equitativo y efectivo a la justicia; y, d) la provisión para las víctimas de recursos eficaces, incluso reparación ${ }^{29}$.

\subsubsection{Prevención de las violaciones}

Los Estados tienen la responsabilidad no sólo de abstenerse de determinado tipo de actos, sino también de proteger a los individuos bajo su jurisdicción de violaciones de derechos humanos. Ello conlleva la obligación positiva de llevar a cabo determinadas políticas, tales como formar a sus funcionarios, reestructurar los modos de trabajo para que las posibilidades de que los agentes gubernamentales lleven a cabo violaciones de derechos humanos se reduzcan al mínimo y desaparezcan, implementar un sistema efectivo de garantías procesales, a través de habeas corpus o de recursos de amparo; etc.

2.2.2. Investigación de las violaciones y enjuiciamiento y castigo a los autores

El derecho internacional requiere que los autores de crímenes internacionales sean llevados ante la justicia para que sean procesados, juzgados y, si se les declara culpables, condenados debidamente ${ }^{30}$. Este requerimiento existe independientemente de los derechos o de la voluntad de las víctimas: es una obligación del Estado.

Además, en estos casos los Estados deben, en conformidad con el derecho internacional, cooperar mutuamente y ayudar a los órganos judiciales internacionales competentes a investigar tales violaciones y enjuiciar a los responsables. Asimismo, deben facilitar la extradición o entrega de culpables a otros Estados y a los órganos judiciales internacionales competentes y prestar asistencia judicial y otras formas de cooperación para la administración de la justicia internacional, en particular la asistencia y protección a las víctimas y testigos ${ }^{31}$.

A pesar de que la competencia territorial de los tribunales nacionales sigue siendo la norma en lo tocante a los delitos graves con arreglo al derecho internacional, estos delitos graves pueden ser enjuiciados en tribunales penales internacionales, cuando los tribunales nacionales no ofrezcan garantías satisfactorias de independencia e imparcialidad o cuando les resulte materialmente imposible desempeñar debidamente sus investigaciones o su seguimiento de

\footnotetext{
${ }^{29}$ Cfr. Informe Redress: Implementando los derechos de las víctimas, cit., 26-28.

30 Ibid., Principio 4.

31 Ibidem.
} 
una causa criminal o no estén dispuestos a ello ${ }^{32}$. También puede suceder que otros Estados se encuentren legitimados para ejercer jurisdicción, por ejemplo, si alguno de sus nacionales ha sido víctima en otro Estado o si el acusado, siendo nacional de un Estado determinado, cometió las violaciones en otro Estado.

Esta evolución de la competencia jurisdiccional ha llevado a que en los Principios y Directrices Básicos sobre Reparaciones se incluya la jurisdicción universal, en el derecho internacional y con respecto a los delitos graves, como un principio que deba incorporarse y aplicarse en los Estados ${ }^{33}$. De este modo, una persona que ha cometido un delito de este tipo podría ser enjuiciado casi en cualquier parte del mundo en que se encontrase ${ }^{34}$.

En ocasiones existen dificultades para iniciar un procedimiento contra los autores de los delitos graves. La necesidad de tiempo por parte de las víctimas para asumir los sucesos y estar preparadas antes de presentarse ante las autoridades y explicar lo sucedido, la necesidad de solucionar otros problemas más inmediatos - económicos, de seguridad, etc.- la existencia de plazos muy cortos de prescripción (lo cual genera un temor a presentar una alegación por temor a represalias), o simplemente, el mantenimiento en el poder del régimen que propició violaciones sistemáticas, son obstáculos a veces insuperables. De ahí que el derecho internacional, y así lo recogen los Principios y Directrices Básicos sobre Reparaciones, establezca que las violaciones manifiestas de las normas internacionales de derechos humanos y la violaciones graves del derecho internacional humanitario que constituyan crímenes en virtud del derecho internacional no prescriben $^{35}$.

32 Cfr. Conjunto de Principios para la Protección y la Promoción de los Derechos Humanos Mediante la Lucha contra la Impunidad, principio 20 (E/CN.4/2005/102/Add.1). Al igual que los Principios y Directrices Básicos sobre Reparaciones, el Conjunto de Principios contra la Impunidad es un trabajo realizado por petición de la Subcomisión de Prevención de Discriminaciones y Protección a las Minorías de las Naciones Unidas (hoy Subcomisión para la Promoción y la Protección de los Derechos Humanos). En 1997, Louis Joinet presentó una primera versión de estos principios (E/CN.4/Sub.2/1997/20/Rev.1). En 2003, se le encargó a Diane Orentlicher que realizase un estudio independiente. En 2005, presentó una nueva versión del Conjunto de Principios contra la Impunidad (E/CN.4/2005/102/Add.1), que recoge la evolución de la práctica y jurisprudencia internacional al respecto. Este texto sigue todavía en fase de trabajo. Los principios contra la impunidad se dividen en tres grandes grupos, de acuerdo con tres derechos: el derecho a saber, el derecho a la justicia y el derecho a obtener reparación (donde se remite a los Principios y Directrices Básicos sobre Reparaciones).

33 Principios y Directrices Básicos sobre Reparaciones, A/RES/60/147, Principio 5.

${ }^{34}$ Cfr., al respecto, el art. 5 Convención contra la Tortura y otros Tratos o Penas Crueles, Inhumanos o Degradantes (UN GA RES 39/46, 10 de diciembre de 1984).

35 Principios y Directrices Básicos sobre Reparaciones, A/RES/60/147, Principio 6. 


\subsubsection{Acceso equitativo y efectivo a la justicia}

La obligación de ofrecer un acceso igual a un recurso efectivo que garantice un desagravio apropiado requiere, en primer lugar, la existencia de instituciones y procedimientos, judiciales y administrativos, a los que las víctimas puedan tener acceso. Ahora bien, los Principios y Directrices Básicos sobre Reparaciones establecen que, en el caso de los delitos graves, los recursos deber ser judiciales ${ }^{36}$. En este sentido, los recursos no judiciales, como por ejemplo los administrativos, no son considerados como un recurso efectivo y adecuado. Asimismo, la existencia de procedimientos administrativos para que las víctimas puedan solicitar una indemnización no puede llevar a una restricción del derecho de las víctimas a presentar una reclamación contra el individuo o contra el Estado ante un órgano judicial.

Además del acceso individual a la justicia, los Principios y Directrices Básicas sobre Reparaciones establecen que los Estados han de procurar establecer procedimientos para que grupos de víctimas puedan presentar demandas de reparación y obtener reparación, según proceda ${ }^{37}$.

En orden a que el acceso a la justicia sea efectivo y equitativo, los Estados están obligados a dar a conocer e informar de todos que los recursos disponibles contra las violaciones, adoptar medidas para minimizar los inconvenientes a las víctimas y sus representantes (proteger su intimidad contra ingerencias ilegítimas, protegerlas de actos de intimidación y represalia, así como a sus familiares y testigos), facilitar asistencia apropiada a las víctimas que buscan el acceso a la justicia, y, finalmente, utilizar los medios jurídicos, diplomáticos y consulares apropiados para que las víctimas puedan ejercer su derecho a interponer recur$\operatorname{sos}^{38}$.

\subsubsection{La reparación y sus formas}

Las víctimas tienen derecho a una reparación adecuada, efectiva y rápida, que ha de ser proporcional a la gravedad de las violaciones y al daño sufrido ${ }^{39}$. Los Estados, por su parte, están obligados a reparar por las acciones u omisiones que puedan atribuírseles, es decir, cuando son directamente responsables por la

\footnotetext{
36 Ibid., Principio 12.

37 Ibid., Principio 13.

38 Ibid., Principio 14.

39 Ibid., Principio 15.
} 
acción u omisión de sus funcionarios o gobernantes. En el caso de que las violaciones no puedan atribuirse al Estado y el responsable de los daños no pueda o no quiera cumplir sus obligaciones, aquél ha de procurar establecer programas de reparación ${ }^{40}$.

Teniendo en cuenta las circunstancias de cada caso la reparación puede adoptar cinco formas: restitución, indemnización, rehabilitación, satisfacción y garantías de no repetición.

a) La restitución, siempre que sea posible, ha de devolver a la víctima a la situación anterior a la violación. Entre otras medidas y según corresponda en cada caso, comprende el restablecimiento de la libertad, el disfrute de los derechos humanos, la identidad, la vida familiar y la ciudadanía, el regreso al lugar de residencia, la reintegración en el empleo, la devolución de los bienes, etc. ${ }^{41}$.

b) No siempre es posible restaurar la situación original de las víctimas, de ahí que sea necesaria la indemnización del daño y del sufrimiento de la víctima y su familia. La indemnización debe concederse, de forma apropiada y proporcional a la gravedad de la violación y a las circunstancias de cada caso, por todos los perjuicios económicamente evaluables (tales como el daño físico o mental) la pérdida de oportunidades (empleo, educación, prestaciones sociales), la pérdida de ingresos, los daños materiales, los perjuicios morales (dolor y sufrimiento, angustia mental, humillación, etc.) y los gastos realizados para obtener una asistencia jurídica o de expertos, medicamentos y servicios psicológicos y sociales ${ }^{42}$.

c) La rehabilitación ha de incluir la atención médica y psicológica, así como servicios jurídicos y sociales. Estos servicios pueden ser provistos directamente, o bien, incluirse como parte de una cantidad económica. En este caso, es importante distinguir entre el dinero que se paga por indemnización y lo que se otorga para cubrir la rehabilitación ${ }^{43}$.

d) La satisfacción cubre una amplia gama de medidas no monetarias que contribuyen a conseguir una reparación en un sentido más amplio y a largo plazo. En concreto, la satisfacción debe incluir, siempre que sea pertinente y procedente, la totalidad o parte de las medidas siguientes ${ }^{44}$ :

i) Medidas eficaces para conseguir que no continúen las violaciones;

ii) La verificación de los hechos y la revelación pública y completa de la verdad, en la medida en que esa revelación no provoque más daños o

40 Ibid., Principio 16.

41 Ibid., Principio 19.

42 Ibid., Principio 20.

43 Ibid., Principio 21.

44 Ibid., Principio 22. 
amenace la seguridad y los intereses de la víctima, de sus familiares, de los testigos o de personas que han intervenido para ayudar a la víctima o impedir que se produzcan nuevas violaciones;

iii) La búsqueda de las personas desaparecidas, de las identidades de los niños secuestrados y de los cadáveres de las personas asesinadas, y la ayuda para recuperarlos, identificarlos y volver a inhumarlos según el deseo explícito o presunto de la víctima o las prácticas culturales de su familia y comunidad;

iv) Una declaración oficial o decisión judicial que restablezca la dignidad, la reputación y los derechos de la víctima y de las personas estrechamente vinculadas a ella;

v) Una disculpa pública que incluya el reconocimiento de los hechos y la aceptación de responsabilidades;

vi) La aplicación de sanciones judiciales o administrativas a los responsables de las violaciones;

vii) Conmemoraciones y homenajes a las víctimas;

viii) La inclusión de una exposición precisa de las violaciones ocurridas en la enseñanza de las normas internacionales de derechos humanos y del derecho internacional humanitario, así como en el material didáctico a todos los niveles.

e) Finalmente, las garantías de no repetición incluyen una serie de medidas que contribuyen a la prevención de futuras violaciones. Mientras que las cuatro primeras formas de reparación están dirigidas directamente a las víctimas, esta última categoría esta dirigida no tanto a reparar a las víctimas en sí, sino a reformar las instituciones y promocionar una cultura de respeto de los derechos humanos. Algunas de estas medidas son ${ }^{45}$ :

i) El ejercicio de un control efectivo de las autoridades civiles sobre las fuerzas armadas y de seguridad;

ii) La garantía de que todos los procedimientos civiles y militares se ajustan a las normas internacionales relativas a las garantías procesales, la equidad y la imparcialidad;

iii) El fortalecimiento de la independencia del poder judicial;

iv) La protección de los profesionales del derecho, la salud y la asistencia sanitaria, la información y otros sectores conexos, así como de los defensores de los derechos humanos;

45 Ibid., Principio 23. 
v) La educación, de modo prioritario y permanente, de todos los sectores de la sociedad respecto de los derechos humanos y del derecho internacional humanitario y la capacitación en esta materia de los funcionarios encargados de hacer cumplir la ley, así como de las fuerzas armadas y de seguridad;

vi) La promoción de la observancia de los códigos de conducta y de las normas éticas, en particular las normas internacionales, por los funcionarios públicos, inclusive el personal de las fuerzas de seguridad, los establecimientos penitenciarios, los medios de información, la salud, la psicología, los servicios sociales y las fuerzas armadas, además del personal de empresas comerciales;

vii) La promoción de mecanismos destinados a prevenir y vigilar los conflictos sociales;

viii) La revisión y reforma de las leyes que contribuyan a las violaciones manifiestas de las normas internacionales de derechos humanos y a las violaciones graves del derecho humanitario o las permitan.

\section{CONCLUSIONES}

La base jurídica de la responsabilidad de un Estado por las violaciones de derechos humanos deriva de una infracción de un tratado de derechos humanos o de una norma de derechos humanos de derecho internacional consuetudinario ${ }^{46}$. La mayoría de los tratados de derechos humanos imponen un deber a los Estados parte de respetar y asegurar los derechos que se reconocen, lo que supone responder a las violaciones cometidas por personas privadas como abstenerse de violaciones autorizadas por el Estado.

Ahora bien, la naturaleza de las obligaciones de derechos humanos es diferente de la de la mayoría del resto de derechos y deberes del derecho internacional. Los tratados y las obligaciones consuetudinarias son por lo general recíprocos o contractuales. Los socios de un tratado se confieren igual beneficios y aceptan a cambio deberes iguales. En consecuencia, la mayoría de los actos que rompen un tratado causan directa y, por lo normal, inmediatamente un daño en los intereses del otro Estado. El Estado que comete el acto ilegal incurre por ello en responsabilidad estatal y tiene el deber de hacer reparaciones por el daño generado. Es el Estado el que afirma que su propio derecho ha

${ }^{46}$ Cfr. Shelton, D.: Remedies in International Human Rights Law, cit., p. 97. 
sido violado, aunque las violaciones las hayan padecido personas individuales ${ }^{47}$.

En contraste, las obligaciones que se derivan de las normas internacionales de derechos humanos tienen el propósito de garantizar el disfrute de los derechos y libertades de los seres humanos individuales, más que establecer relaciones recíprocas entre Estados. Como ha señalado la Comisión Europea de Derechos Humanos, refiriéndose al Convenio Europeo, «el propósito de las Altas Partes Contratantes al aprobar el Convenio no fue concederse derechos y obligaciones recíprocas con el fin de satisfacer sus intereses nacionales, sino realizar los fines e ideales del Consejo de Europa (...) y establecer un orden público común de las democracias libres de Europa con el objetivo de salvaguardar su herencia común de tradiciones políticas, ideas y régimen de derecho» ${ }^{48}$. Por ello, «las obligaciones asumidas por las Altas Partes Contratantes en el Convenio son esencialmente de carácter objetivo, diseñadas para proteger los derechos fundamentales de los seres humanos de violaciones de parte de las Altas Partes Contratantes en vez de crear derechos subjetivos y recíprocos entre las Altas Partes Contratantes ${ }^{49}$.

Este carácter especial de los tratados de derechos humanos ha sido reconocido también por la Corte Interamericana de Derechos Humanos al declarar que "[1] os tratados modernos de derechos humanos, en general, y, en particular, la Convención Americana, no son tratados multilaterales del tipo tradicional, concluidos en función de un intercambio recíproco de derechos, para el beneficio mutuo de los Estados contratantes. Su objeto y fin son la protección de los derechos fundamentales de los seres humanos, independientemente de su nacionalidad, tanto frente a su propio Estado como frente a otros Estado contratantes. $\mathrm{Al}$ aprobar esos tratados sobre derechos humanos, los Estados se someten a un orden legal dentro del cual ellos, por el bien común, asumen varias obligaciones, no en relación con otros Estados, sino hacia los individuos bajo su jurisdicción $»^{50}$.

Este distinto enfoque entre uno y otro sistema tiene una gran repercusión en cómo entienden cada uno de ellos quién es víctima de una violación, quién ha cometido la violación y qué consecuencias conlleva. Mientras que en el ámbito

47 Cfr. Ibid., 98.

48 "Austria vs. Italy", Application N ${ }^{\circ} 788 / 60$, Yearbook of the European Convention on Human Rights, 4, 1961, 138.

49 Ibid., p. 140.

50 El efecto de las reservas sobre la entrada en vigencia de la Convención Americana sobre Derechos Humanos (arts. 74 y 75). Opinión consultiva OC-2/82 de 24 de septiembre de 1982. (1982). Corte I.D.H. (Ser. A) No 2. 
de la responsabilidad estatal los autores de las violaciones y las víctimas son los Estados, en el de los derechos humanos las víctimas son las personas tomadas individual o colectivamente, con independencia de si el autor de la violación ha sido identificado. La víctima tampoco requiere ser reconocida por el Estado del que es nacional para ser considerado víctima. La violación flagrante de derechos humanos genera asimismo la obligación de investigar, procesar y castigar a los infractores, para lo cual los Estados deben cooperar entre sí y con los órganos judiciales internacionales.

Las diferencias entre uno y otro sistema afectan también al ámbito y naturaleza de las medidas de reparación. Como se ha señalado, la finalidad de la reparación en el derecho internacional de responsabilidad estatal es la restauración del status quo ante, estableciéndose una jerarquía entre las distintas medidas: en primer lugar, la restitución; en la medida en que no sea posible, la indemnización; y, finalmente, la satisfacción como medida únicamente excepcional. Es la reparación típica entre dos partes contratantes.

Por el contrario, en las reparaciones a violaciones flagrante a los derechos humanos, la finalidad no es, ni puede ser, tan sólo la restauración del status quo ante. En primer lugar, porque muchas veces esa restauración no es posible ni mediante la restitución ni mediante una indemnización, ya sea por la naturaleza de las violaciones (muertes, desapariciones, torturas, etc.), por el abundante número de víctimas o perpetradores, por la imposibilidad de identificar a éstos últimos, o por la situación social, económica, y política en la que se encuentra el país donde residen las víctimas, entre otras razones. Y, en segundo lugar, porque las reparaciones, en esas situaciones, deben ajustarse a conseguir la cesación del conflicto, la prevención de errores futuros, la disuasión de nuevos atentados, la rehabilitación de la sociedad y de las víctimas y, en último extremo, la reconciliación entre grupos. De ahí que las medidas de satisfacción y las garantías de no repetición sean tan importantes en estos casos.

Junto a esto, en las reparaciones a las víctimas de violaciones flagrantes de los derechos humanos, uno de los elementos más importante y necesario es reparar el estatus de las víctimas como ciudadanos, integrándolos plenamente en la sociedad. El daño que sufren estas víctimas no es sólo corporal o material, sino también político, en la medida en que la acción violenta, en muchas ocasiones, tiene como finalidad la negación de su condición de ciudadano, su reducción a no-sujeto ${ }^{51}$. Reparar el daño supone, evidentemente, reparar el daño personal en

${ }^{51}$ Ver al respecto, MATE, R.: Justicia de las víctimas. Terrorismo, memoria, reconciliación, Barcelona, Anthropos, 2008, pp. 38-43. 
la medida de lo posible; aunque en muchas ocasiones esta daño sea irreparable. Pero, junto a este tipo de reparación, es necesario hacer frente al daño político, mediante el reconocimiento social de la ciudadanía, esto es, el reconocimiento por parte de la sociedad de que la víctima es parte de ella y que sin ella nadie es ciudadano. Esto se consigue, precisamente con medidas simbólicas, con una política de lugares de la memoria, gracias a la cual las víctimas alcancen una visibilidad social e institucional.

Pero, por ello mismo, frente a lo que se sostiene en los Principios y Directrices Básicos sobre Reparaciones, los procesos judiciales tienden a ser una manera muy incompleta de solucionar el reto que representan las víctimas ${ }^{52}$. Los tribunales sólo tienen capacidad suficiente para atender a un número limitado de casos. Más aún, es posible que se exija a las víctimas la presentación de pruebas detalladas de los delitos, de las lesiones o pérdidas materiales sufridas, e incluso, en algunas ocasiones, de la identidad del autor del crimen. Lo cual es habitualmente imposible. Por otra parte, aquellas víctimas desprovistas de recursos o de acceso a una asesoría jurídica y a los tribunales con frecuencia no obtienen una reparación, aun cuando sufren iguales daños.

Un procedimiento caso por caso genera dos problemas adicionales. En primer lugar, disgrega a las víctimas, debido al desigual acceso a los tribunales y a las desiguales compensaciones que otorgan, lo cual genera una jerarquización de las víctimas ${ }^{53}$. En segundo lugar, disgrega los esfuerzos de reparación, ya que, por

52 Cfr. al respecto, DE GREIFF, P.: «Los esfuerzos de reparación en una perspectiva internacional: el aporte de la compensación al logro de la justicia imperfecta», CASAS, R. (trad.), Estudios Socio-Jurídicos, 7, 2005, pp. 153-199; MAgARrelL, L.: Reparations in Theory and Practice, New York, ICTJ, 2007; y, Oficina del Alto Comisionado de las NaCiOnes Unidas para los DeRECHOS Humanos: Instrumentos del Estado de Derecho para sociedades que han salido de un conflicto. Programas de reparaciones, Nueva York y Ginebra, Naciones Unidas, 2008.

53 Un ejemplo paradigmático de este problema viene dado por el modo de indemnizar a las víctimas de terrorismo en España. Así, en las sentencias contra terroristas pertenecientes a la banda terrorista ETA, en las que se establece una indemnización por responsabilidad civil por fallecimiento, los jueces han otorgado en los últimos años indemnizaciones entre $300.000 \Leftrightarrow$ y $1.000 .000 \Leftrightarrow$. Este desfase entre unas indemnizaciones y otras se debe, en gran medida, a que la cuantificación de los daños y perjuicios, cuando consisten en daños corporales, no se halla sujeta a previsión normativa alguna, sino que la efectúa el órgano jurisdiccional discrecionalmente (así lo ha mantenido de forma constante la jurisprudencia del Tribunal Supremo. Cfr. entre otras, SSTS de 1 de julio de 1988, de 25 de enero de 1990 y de 21 de febrero de 1991). Asimismo, el importe de esta indemnización no es revisable en casación, ya que pertenece a la soberanía exclusiva del tribunal a quo. Esto conlleva que los criterios dispares de los jueces y tribunales no puedan ser unificados por el Tribunal Supremo. Cfr. Fuster-Fabra Torrellas, J. M.: Responsabilidad civil derivada de actos de terrorismo, Barcelona, Atelier, 2001, pp. 76-79. Este problema no ha sido 
la naturaleza fragmentada del proceso, éste no se coordina con otras medidas de justicia transicional, como son la persecución de los criminales, la búsqueda de la verdad y los cambios institucionales ${ }^{54}$. De ahí que, para reparar convenientemente a este tipo de víctimas, sea necesario ir más allá del ámbito judicial y establecer legislativamente programas de reparación concretos y determinados. Con este tipo de programas es la propia sociedad la que reconoce un conjunto de derechos a las víctimas desde una perspectiva ética y política, compensando así, en la medida de lo posible, los olvidos, la invisibilidad y la incomprensión que estas víctimas han sentido y sufrido.

resuelto por la Ley 32/1999, de 8 de octubre, de Solidaridad con las Víctimas del Terrorismo. Más bien, lo ha agudizado. De acuerdo con esta ley, si existe sentencia firme reconociendo una indemnización por una serie determinada de daños físicos o psicofísicos en concepto de responsabilidad civil, se abona la cantidad fijada. Si no existe sentencia firme, o si ésta no reconoce o no permite reconocer una cantidad en concepto de responsabilidad civil, se abona una cuantía establecida por baremo. Así, la cantidad fijada por el baremo para los casos de fallecimiento es de $138.232,78 \Leftrightarrow$. Al diferenciar entre aquellas indemnizaciones que están fijadas por sentencia y aquellas otras que lo están por baremo, por no existir todavía sentencia, esta ley establece dos tipos de víctimas, aunque el atentado terrorista tenga las mismas consecuencias. Por un lado están aquellas víctimas sujetas a un baremo y por otro aquellas que debido a la discrecionalidad, en estos casos generosa, del juez, obtendrán una mayor indemnización. Incluso dentro de este grupo de víctimas, como se ha dicho, hay unas que son indemnizadas con una mayor cuantía que otras, ya que los jueces no tienen un mismo criterio a la hora de establecer la indemnización. De este modo, se produce una nueva victimización. Toda víctima sufre las consecuencias de un atentado. Ahora bien, el sufrimiento se agudiza en la medida en que la víctima y sus familiares no saben quién llevo a cabo y cómo se produjo ese atentado. Este sufrimiento puede ser mayor al ver cómo aquellas víctimas y familiares que sí saben quién y cómo se cometió son tratadas con mayor generosidad que ellas.

${ }^{54}$ La justicia transicional puede ser definida como la concepción de la justicia asociada con períodos de cambio político, caracterizados por respuestas jurídicas que tienen el objetivo de hacer frente a un legado de violaciones graves de derechos humanos. Esto conlleva generalmente una combinación de estrategias judiciales y no judiciales complementarias como son el procedimiento contra los responsables, el establecimiento de comisiones de la verdad y otras formas de investigar el pasado, el desarrollo de programas de reparación para los afectados por la violencia política, la memoria y el recuerdo de las víctimas y la reforma de todas las instituciones que han contribuido a las violaciones. Cfr. KRITZ, N. (ed.). Transitional Justice: How Emerging Democracies Reckon with Former Regimes, 3 vols., Washington, Institute of Peace Press, 1995; TeITEL, R. G.: "Transitional Justice Genealogy», Harvard Human Rights Journal, 16, 2003, pp. 69-94; y BICKFORD, L.: "Transitional Justice», en SHELTON, D. (ed.), Encyclopedia of Genocide and Crimes Against Humanity, vol. 3, Detroit, Macmillan Reference, 2005, pp. 1045-1047. 
Title

THE RIGHT TO A REMEDY AND REPARATION IN THE INTERNATIONAL LAW. A COMPARATIVE STUDY BETWEEN THE INTERNATIONAL LAW OF STATE RESPONSIBILITY AND THE BASIC PRINCIPLES ON THE RIGHT TO A REMEDY AND REPARATION FOR HUMAN RIGHTS VICTIMS.

\section{Summary}

I. THE RIGHT TO A REMEDY AND REPARATION IN THE INTERNATIONAL LAW OF STATE RESPONSIBILITY. 1. The multilateral context: the restoration and preservation of the rule of law. 2. The aim of the reparation. II. THE RIGHT TO A REMEDY AND REPARATION IN THE INTERNATIONAL LAW OF HUMAN RIGHTS. 1. Genesis and development of the Basic Principles and Guidelines on Reparations. 2. Content of the Basic Principles and Guidelines on Reparations. 2.1. Area of application. 2.1.1. The victims. 2.1.2. The violations. 2.2. Structure of the Basic Principles and Guidelines on Reparations. 2.2.1. Prevention of the violations. 2.2.2. Investigation of the violations and actions against the perpetrators. 2.2.3. Equal and effective access to justice. 2.2.4 The reparations and its forms. III. CONCLUSIONS.

\section{Resumen}

En este artículo se analizan los textos más importantes en el ámbito de reparación a las víctimas en el ámbito internacional y que reflejan las características esenciales tanto del derecho internacional de responsabilidad estatal como del derecho internacional de los derechos humanos. Por un lado, los Artículos sobre la Responsabilidad del Estado por hechos internacionalmente ilícitos, adoptados por la Comisión de Derecho Internacional de las Naciones Unidas en 2001. Por otro lado, los Principios y Directrices Básicos sobre el Derecho de las Victimas de Violaciones Manifiestas de las Normas Internacionales de Derechos Humanos y de Violaciones Graves del Derecho Internacional Humanitario a Interponer Recursos y Obtener Reparaciones, aprobados por la Asamblea General de las Naciones Unidas en 2005. Estos textos articulan, cada uno en su ámbito, aquellos principios que han sido aplicados en el los tribunales internacionales y que gozan de un amplio consenso en el derecho internacional. El objetivo del artículo es identificar los elementos comunes así como los elementos característicos de cada uno de ellos, en orden a mostrar sus logros y deficiencias a la hora de reparar a las víctimas de violaciones de derechos humanos. 


\begin{abstract}
In this article are analyzed the most important texts in the area of reparations to the victims in the International Law and that reflect the essential characteristics of the International Law of State Responsibility and of the International Law of the Human Rights. On the one hand, the Articles on Responsibility of States for Internationally Wrongful Acts, adopted by the United Nations International Law Commission (ILC) in 2001. On the other one, the Basic Principles and Guidelines on the Right to a Remedy and Reparation for Victims of Gross Violations of International Human Rights Law and Serious Violations of International Humanitarian Law, approved by the United Nations General Assembly in 2005. These texts articulate, each one in their scope, those principles that have been applied in the international courts and that enjoy a wide consensus in the International Law. The aim of the article is to identify the common elements as well as the elements characteristic of each one of them, in order to show theirs achievements and deficiencies at the moment of repair victims of human rights violations.
\end{abstract}

\title{
Palabras clave
}

Reparación, Derecho a una reparación, Víctimas, Violaciones de derechos humanos.

\section{Key Words}

Reparation, Right to a Remedy, Victims, Human Rights Violations. 
